\title{
Do direito à educação à perspectiva ressocializadora: análise de uma escola pública em uma penitenciária
}

\author{
The right to education in a ressocializing perspective: analisys of a \\ public school in the penitentiary
}

http://dx.doi.org/10.5007/2178-4582.2016v50n2p459

\author{
Natanael Ítalo Aleixo da Costa Marreiros \\ Universidade de Pernambuco, Petrolina/PE, Brasil
}

\begin{abstract}
Neste artigo, apresentam-se os resultados de estudos realizados na Escola Estadual Bento XVI, localizada no presídio Doutor Edvaldo Gomes na cidade de Petrolina - PE. Essa atividade se constitui como requisito para a conclusão do curso de Licenciatura em Pedagogia na Universidade de Pernambuco - Campus Petrolina. A pesquisa teve como objetivo analisar as propostas de ensino da referida instituição, se estavam de acordo com as Diretrizes Curriculares Nacionais para oferta de educação de jovens e adultos em situação de privação de liberdade nos estabelecimentos penais. Primeiramente, foi feita uma explanação sobre a Educação de Jovens e Adultos no Brasil e, em seguida, no âmbito do sistema prisional brasileiro em perspectiva histórica. Por fim, trata-se da educação como proposta política para a ressocialização. Conclui-se que um dos maiores entraves para que de fato aconteça a educação ressocializadora é a falta de incentivo e capacitação dos profissionais envolvidos nesse processo.
\end{abstract}

Palavras-chave: EJA; Ressocialização; Prisões; Direito.
This study presents the results from a research held at State School Bento XVI, in the prison Doutor Edvaldo Gomes in Petrolina - PE. The activity constituted a requisite to conclude the Pedagogy course in Pernambuco University-Campus Petrolina. The research aimed to analyze teaching proposals in the mentioned institution, whether they were in accordance to the National Curricular Guidelines regarding youngsters and adults' education in liberty depravation inside penitentiaries. Firstly, an explanation about youngsters and adults' education within the scope of the Brazilian in a historical perspective. Then, education as a political policy for ressocialization is approached. The conclusion is that one of the biggest obstacles for this ressocialization through education is the lack of stimulus and professional capacitation.

Keywords: Youngsters and Adults' Education; Ressocialization; Prisons; Law.

\section{Introdução}

\begin{abstract}
As ações educativas devem exercer uma influência edificante na vida do interno, criando condições para que molde sua identidade, buscando, principalmente, compreender-se e aceitar-se como indivíduo social; construir seu projeto de vida, definindo e trilhando caminhos para a sua vida em sociedade (BRASIL, 2010, p. 14).
\end{abstract}

Este artigo é resultado de pesquisa de campo realizada na Escola Estadual Bento XVI, situada na Penitenciária Doutor Edivaldo Gomes, Avenida Fazenda Jatobá, número 640, bairro Jatobá, Petrolina - PE, inaugurada em 2012, por meio do decreto . $^{\circ} 37717$ de 29/12/2011, com o intuito de oferecer um ambiente educativo para os apenados. 
A educação de jovens e adultos em uma visão ressocializadora dentro dos presídios tem sido tema de muitos trabalhos acadêmicos e os resultados têm apontado a existência de preconceitos sobre o processo de aprendizagem para a ressocialização dos apenados ${ }^{1}$.

O estudo se justifica pela carência de dados a respeito desse tipo de educação que motiva grandes discussões em todo país, mas ainda tem sido pouco difundida. Sobre essa questão, Santos (2005) explica que é preciso desenvolver programas educacionais nos sistemas penitenciários direcionados para a educação básica de jovens e adultos com o objetivo de alfabetizar e, principalmente, lutar para a construção da cidadania do detento. Assim, o apenado passa a ser preparado para o convívio com os outros indivíduos, tendo consciência do seu papel enquanto cidadão na sociedade.

Dados disponíveis no Portal Brasil (2014) demonstram que a cada dez detentos apenas um participa de atividades educacionais, $66 \%$ da população presidiária não concluíram o ensino fundamental, menos de $8 \%$ têm ensino médio e a mesma proporção é analfabeta. Grande parte dos apenados são compostos por jovens com menos de trinta anos, de baixa escolaridade, que não tiveram oportunidade de concluir seus estudos por várias razões - uma delas é a iniciação ao mundo do crime. Daí a necessidade de um trabalho minucioso dentro das penitenciárias, a partir de projetos educacionais que estimulem os educandos à compreensão do seu papel como sujeitos históricos e sociais.

Diante do exposto, este estudo demonstra relevância acadêmica e social e tem o intuito de desmistificar alguns estigmas acerca da ressocialização de detentos, algumas vezes discriminados e colocados à margem da sociedade, sendo tratados como um "caso perdido".

O preconceito é uma primeira percepção, em geral, parcial, incompleta, fosca, de alguma coisa; torna-se negativo quando permanecemos nele, sem desenvolvê-lo. Aí ele nos limita, nos impede de ver as coisas de uma maneira mais ampla e transparente (BORGES, 2011).

A pesquisa configurou-se como exploratória, em que é possível, na sua elaboração, delimitar o tema, definir os objetivos e levantar questionamentos. Concomitantemente, Cajueiro (2013) afirma que a pesquisa exploratória visa estudar, explorar o problema a fim de torná-lo explícito e possibilitar a criação de questões. Por conseguinte, ela possui um caráter qualitativo, que considera que há uma relação dinâmica entre o real e o sujeito, entre o mundo objetivo e o subjetivo, que não podem ser traduzidas em números (OTONI; FIALHO, 2011). A coleta de dados foi realizada no período de 28 de outubro a 18 de novembro de 2011. O levantamento foi feito por meio de análise do

Sobre a ressocialização nos presídios ver, entre outros, Costa (2014), Julião (2011), Teixeira (2007). 
Projeto Político Pedagógico da instituição, entrevistas semiestruturada na qual foi organizada por meio de um roteiro com questionamentos predefinidos, mas, dando abertura para o surgimento de outros questionamentos, as mesmas foram realizadas com a gestora adjunta e três professoras, observações nos diversos ambientes da escola tais como secretaria, sala de professores, corredores, sala de leitura e sala de aula.

Espera-se com esse trabalho contribuir para a ampliação dos estudos que se debruçam sobre a educação de jovens e adultos nos presídios como objeto de análise. Partindo dessa premissa, surgiu o seguinte questionamento: as propostas de ensino da Escola Estadual Bento XVI estão de acordo com as Diretrizes Curriculares Nacionais para oferta de educação de jovens e adultos em situação de privação de liberdade nos estabelecimentos penais?

O trabalho está organizado em três seções. A primeira, Educação de jovens e adultos no Brasil: apontamentos iniciais, expõe os principais marcos na de sua trajetória no Brasil, resultando na criação de suas Diretrizes.

A segunda seção, Educação de jovens e adultos do sistema prisional brasileiro em perspectiva histórica, faz um detalhamento do processo da educação no Brasil, resultante das Diretrizes Curriculares Nacionais para oferta de educação de jovens e adultos em situação de privação de liberdade nos estabelecimentos penais.

A terceira, Educação como proposta política para a ressocialização, trata da educação como instrumento fundamental para a ressocialização dos presos, destacando a atuação da escola como agente desse processo.

\section{Educação de jovens e adultos do Brasil: apontamentos iniciais}

A Educação de Jovens e Adultos (EJA) é uma modalidade de ensino amparada por lei, visando atingir as pessoas que não tiveram acesso à educação regular por algum motivo. No Brasil, a lei ainda é muito recente, embora o tema não seja novo; remonta ao período colonial. Nesse período, a educação de adultos no Brasil colônia resumia-se apenas ao ensino religioso, abrangendo mais um caráter religioso que educacional ${ }^{2}$. A educação brasileira nessa época tinha um direcionamento para as crianças, mas indígenas adultos foram submetidos a uma intensa ação cultural e educacional: a Companhia Missionária de Jesus visava a catequização (iniciação à fé) e alfabetização na língua portuguesa dos indígenas que viviam na colônia brasileira (STRELHOW, 2010).

2

Em 1759, os Jesuítas saem do Brasil. Nesse período, a educação de adultos entra em crise, ficando sob responsabilidade do Império, sendo marcada pelo elitismo, ou seja, a educação fica monopolizada para as classes dominantes. Já em 1824, com a Constituição Imperial, objetivou-se dar significado mais amplo para a educação, garantindo a todos os cidadãos a instrução primária, mas essa lei não teve serventia, ficando apenas no papel (STRELHOW, 2010). 
A partir da Constituição Imperial de 1824, tentou-se dar um significado mais amplo à educação, garantindo aos cidadãos a instrução primária, mas a referida lei não passou do papel. Havia um grande debate em todo o Império sobre como atender a educação formal das camadas inferiores formadas por homens e mulheres pobres e livres, negras e negros escravos, livres e libertos. No Ato Constitucional de 1834, as províncias ficam com a responsabilidade da instrução primária e secundária de todas as pessoas, porém focada mais para a educação de adultos, carregada de um princípio missionário e caridoso (STRELHOW, 2010).

Com o desenvolvimento industrial no século $\mathrm{XX}$, surge a necessidade de se acabar com o analfabetismo, a falta de investimentos na educação sendo a principal causa da estagnação econômica do país. Valorizava-se o domínio da língua escrita, objetivando o controle das técnicas de produção, para o progresso do país e ampliação da base de votos. No artigo 'Trajetória da escolarização de jovens e adultos no Brasil: de plataformas de governo a propostas pedagógicas esvaziadas', as autoras enfatizam que:

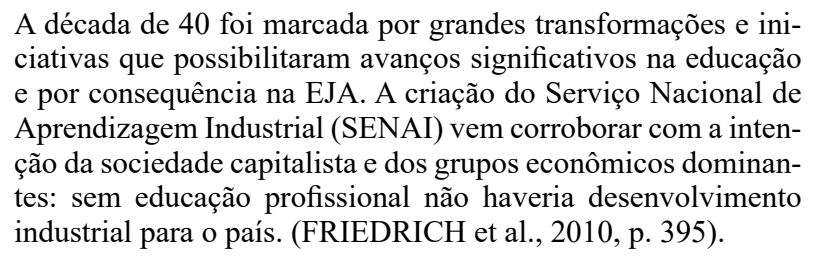

Com as iniciativas nos níveis estadual e local, foram criados o Fundo Nacional de Ensino Primário em 1942, o Serviço de Educação de Adultos e a Campanha de Educação de Adultos, ambos em 1947, a Campanha Nacional de Educação Rural (CNER) iniciada em 1952 e a Campanha Nacional de Erradicação do Analfabetismo (CNEA) em 1958. "CNER, em 1952, buscou, por intermédio de missões rurais e centros de treinamentos, melhorar as condições de trabalho e a qualidade de vida dos habitantes da zona rural" (ÁVILA, 2013, p. 157). Nesse momento as discussões lideradas por Paulo Freire ganham força, sentindo a necessidade de romper com os preconceitos que sofriam as pessoas analfabetas. $\mathrm{O}$ analfabetismo era concebido como causa e não efeito da situação econômica, social e cultural do país (PIERRO; JOIA; RIBEIRO, 2001).

Os principais movimentos deflagrados no final da década de 50 foram: Movimento de Educação de Base (1961-CNBB), Movimento de Cultura Popular do Recife (1961), Centros Populares de Cultura (UNE), Campanha De Pé No Chão Também Se Aprende (Prefeitura de Natal). No mesmo ano em que se encerrou a CNEA, Paulo Freire foi indicado para elaborar o Plano Na- 
cional de Alfabetização junto ao Ministério da Educação, sendo interrompido pelo Golpe Militar em 1964 (STRELHOW, 2010). Na mesma época, Paulo Freire é exilado e o governo assume o controle da alfabetização em 1967, criando o Movimento Brasileiro de Alfabetização - MOBRAL para as pessoas de 15 a 30 anos, com um caráter de alfabetização funcional ${ }^{3}$.

Com o fim da ditadura militar em 1985 e o início da Nova República, o MOBRAL é extinto, surgindo a Fundação EDUCAR, abrindo mão de executar diretamente os projetos e passando a apoiar financeira e tecnicamente as iniciativas existentes. Em 1971, surge o ensino supletivo no país. Ampliou-se o dever do Estado, garantindo o ensino fundamental obrigatório e gratuito para todos, com a promulgação da Constituição de 1988. A fundação é extinta sem nenhum outro projeto ser criado em seu lugar no Governo Collor, em 1990. A partir daí o governo federal abandona os projetos da EJA, deixando os municípios na incumbência de realizar a mesma.

Em 1990, foi criado o MOVA - Movimento de Alfabetização, que tinha a incumbência de trabalhar a alfabetização partindo do contexto socioeconômico das pessoas analfabetas, tornando-as participantes ativos de seu processo de aprendizagem. Já em 1996 o governo federal retoma a organização de projetos, resgatando o Programa Alfabetização Solidária (PAS), bem parecidos com os das décadas de 40 e $50^{4}$.

A Lei de Diretrizes e Bases da Educação Nacional n. ${ }^{\circ}$ 9.394/96 assegura a educação para aqueles que não puderam dar continuidade de estudos no ensino fundamental e médio na idade própria, a educação como direito social à cidadania. Nesse sentido, a referida lei determina que:

Art. 1. ${ }^{\circ}$ A educação abrange os processos formativos que se desenvolvem na vida familiar, na convivência humana, no trabalho, nas instituições de ensino e pesquisa, nos movimentos sociais e organizações da sociedade civil e nas manifestações culturais.

Art. 4. ${ }^{\circ}$ O dever do Estado com a educação escolar pública será efetivado mediante a garantia de:

VII. oferta de educação escolar regular para jovens e adultos, com características e modalidades adequadas às suas necessidades e disponibilidades, garantindo-se aos que forem trabalhado-

\footnotetext{
3 Presidentes na década de 60: Jânio Quadros (1961), João Goulart (1961-1964), Humberto Castelo Branco (1964-1967).

4 No fim da década de 1990, foi criado o PRONERA - Programa Nacional de Educação na Reforma Agrária, com o objetivo de atender às populações de assentamentos, vinculado diretamente com o Incra, universidades e movimentos sociais.
} 
res as condições de acesso e permanência na escola (BRASIL, 1996, p. 1).

A EJA é garantida por lei, munida de características diferentes do ensino regular, exigindo do estado uma organização especial para garantir o acesso e permanência dessas pessoas. O Conselho Nacional de Educação - CNE e a Câmara de Educação Básica - CEB, visando o cumprimento das leis superiores, estabelecem as Diretrizes Curriculares Nacionais para a referida educação, por meio do Parecer N..$^{\circ} 11$, de maio de 2000 , reconhecendo a mesma como:

[...] uma dívida social não reparada para com os que não tiveram acesso a e nem domínio da escrita e leitura como bens sociais na escola ou fora dela [...] em que a ausência de escolarização não pode e nem deve justificar uma visão preconceituosa do analfabeto ou iletrado como inculto [...] (BRASIL, 2000, p. 5).

Já no item IX do parecer, reafirma a necessidade de uma Proposta Pedagógica específica da educação de jovens e adultos, tendo um caráter contextualizado, ou seja, estes estudantes podem dispor de seu tempo e de seu espaço, não permitindo uma heterogeneidade dos educandos (BRASIL, 2000).

Esse parecer remete à desconstrução dos velhos métodos empregados na nessa modalidade de ensino, que eram os mesmos utilizados na educação infantil, ocasionando o desinteresse por parte dos estudantes. Parafraseando as ideias de Ceratti (2007), os conteúdos propostos e os assuntos discutidos, tal como as atividades desenvolvidas, devem ser direcionados aos adultos no âmbito da vivência deles. Essa diferenciação de ensino abrange as questões de horários apropriados, especialmente noturno, descontextualização da idade escolar da própria infância, entre outros fatores metodológico-políticos.

A busca da alfabetização ou da complementação de estudos participa de um projeto mais amplo de cidadania que propicie inserção profissional e busca da melhoria das condições de existência. Portanto, o tratamento dos conteúdos curriculares não pode se ausentar desta premissa fundamental, prévia e concomitante à presença em bancos escolares: a vivência do trabalho e a expectativa de melhoria de vida (BRASIL, 2000, p. 57).

Como determina a legislação, a educação de jovens e adultos privilegia o trabalho, uma vez que faz parte do universo dos alunos, devendo perpassar os conteúdos estudados e o currículo destinado a eles. Esse parecer almeja fortalecer essa modalidade de ensino que por muitos anos foi marginalizada pelo descompromisso das políticas educacionais vigentes para com esse público. 
Já em 2003, foi criado o Programa Brasil Alfabetizado (PBA) pelo governo federal, objetivando:

Promover a superação do analfabetismo entre jovens com 15 anos ou mais, adultos e idosos e contribuir para a universalização do ensino fundamental no Brasil. Sua concepção reconhece a educação como direito humano e a oferta pública da alfabetização como porta de entrada para a educação e a escolarização das pessoas ao longo de toda a vida (BRASIL, 2003, p. 1).

O PBA possui um caráter voluntário com o prazo de 4 anos para erradicar o analfabetismo, porém o mesmo perdura até o presente ano.

\section{Educação de jovens e adultos do sistema prisional brasileiro em perspectiva histórica}

Os marcos regulatórios da educação de jovens e adultos privados de liberdade no Brasil ainda são recentes, a sua consolidação é resultado de diversas discussões.

Em 1955, a Organização das Nações Unidas (ONU) lança as Regras Mínimas para o Tratamento de Prisioneiros e, nos seus itens 40 e 77, estabelece que:

40.

Cada estabelecimento prisional terá uma biblioteca para o uso de todas as categorias de presos, devidamente provida com livros de recreio e de instrução, e os presos serão estimulados a utilizá-la.

Educação e recreio [...].

77.

1.Serão tomadas medidas para melhorar a educação de todos os presos em condições de aproveitá-la, incluindo instrução religiosa nos países em que isso for possível. A educação de analfabetos e presos jovens será obrigatória, prestando-lhe a administração especial atenção.

2.Tanto quanto possível, a educação dos presos estará integrada ao sistema educacional do país, para que depois da sua libertação possam continuar, sem dificuldades, a sua educação (ONU, 1955, p. 7-14).

Esse foi o primeiro passo que impulsionou o Brasil na promoção da educação. As unidades prisionais teriam que criar espaços de leitura e obrigato- 
riamente oferecer, aos analfabetos, educação. Apesar da escassez de estudos acerca da educação em prisões, segundo Silva (2011), há registros da existência desse tipo de educação desde os anos 60 , em quase todas as unidades da federação.

A educação carcerária no Brasil foi garantida em 1984, por meio da Lei de Execução Penal (LEP) ${ }^{5}$, tratando-a como dever do Estado, atendendo a instrução escolar e a formação profissional. Essa lei traz benefícios para os detentos estabelecendo o $1 .^{\circ}$ Grau como obrigatório, ensino profissional em nível de iniciação ou aperfeiçoamento, convênios com entidades públicas ou particulares, e, em consonância com as Regras Mínimas para o Tratamento de Prisioneiros da ONU, a criação de bibliotecas nos estabelecimentos prisionais, com livros diversos.

A educação dos detentos também é garantida pela Carta Magna em 1988, no seu artigo 205, como um direito de todos e dever do Estado e da família. Vale ressaltar que o detento está privado de seu direito de ir e vir, ou seja, de liberdade, mas não do seu direito à educação. Desse modo tal, não pode the ser negado.

Já em 1990, foram aprovadas as resoluções n. ${ }^{\circ} 1990 / 20$, n. ${ }^{\circ} 1990 / 24$, n. $^{\circ}$ 45/111 e n. $.^{\circ} 45 / 122$ pelo Conselho Econômico e Social da ONU, que contribuíram para o aperfeiçoamento da educação carcerária em todo o país (BRASIL, 2010). O Brasil, por ser um país membro da ONU, em 1994 cria a resolução n. ${ }^{\circ} 14$, estabelecendo as Regras Mínimas para o Tratamento de Presos no Brasil (BRASIL, 1994). No mesmo ano, cria-se a lei complementar n. ${ }^{\circ}$ 79, que instituiu o Fundo Penitenciário Nacional (FUNPEN), objetivando a modernização dos espaços prisionais e comtemplando a implantação de medidas pedagógicas, formação educacional e cultural, entre outras.

É importante notar que a Lei de Diretrizes e Bases da Educação (LDB), de 1996, não considerou a educação nos sistemas prisionais. Somente em 2001, por meio da Lei n. ${ }^{0} 10.172$, de 9 de janeiro, abriu-se espaço para a formulação de novos planos. A mesma objetivou:

[...]a elevação global do nível de escolaridade da população; a melhoria da qualidade do ensino em todos os níveis; a redução das desigualdades sociais e regionais no tocante ao acesso e à permanência, com sucesso, na educação pública e democratização da gestão do ensino público, nos estabelecimentos oficiais, obedecendo aos princípios da participação dos profissionais da educação na elaboração do projeto pedagógico da escola e a participação das comunidades escolar e local em conselhos escolares ou equivalentes (BRASIL, 2001, p. 1).

$5 \quad$ Os direitos a assistência educacional encontram-se nos artigos 10,17, 18, 19, 20 e 21 da $\operatorname{LEP}^{\circ}$ 7.210, de julho de 1984. 
Assim, o Plano Nacional de Educação em Direitos Humanos, na sua meta 26, corrige esse déficit, estabelecendo a criação de programas para garantir a educação básica dentro das penitenciárias.

Após amplos debates realizados pelo Governo Federal e diversas entidades envolvidas na luta pelos direitos humanos, em 2005, é que foram realizados seminários regionais sobre educação nas prisões em 2006 e 2007, construindo um acervo de sugestões para a elaboração das Diretrizes Nacionais para a oferta de educação de jovens e adultos em situação de privação de liberdade nos estabelecimentos penais (BRASIL, 2010).

Em 2007, foi criada a Lei n. ${ }^{\circ} 11.530$, instituindo o Programa Nacional de Segurança Pública com Cidadania (PRONASCI), que visava a melhoria da segurança pública por meio da articulação de órgãos federais. No ano subsequente, ela é alterada em seus artigos $2 .^{\circ}, 3 .^{\circ}, 4 .^{\circ}, 6 .^{\circ}$ e $9 .^{\circ}$ pela Lei n. ${ }^{\circ}$ $11.707 / 2008$, a fim do seu aprimoramento. O PRONASCI é um projeto de grande importância, pois tem como ideia central a articulação de ações de segurança pública para estabelecer políticas sociais para jovens e adolescentes egressos do sistema prisional.

A criação das Diretrizes Nacionais para a Educação nos Presídios é resultante desses movimentos, que entrou em discussão no ano de 2009, na Câmara de Educação Básica (CEB), sendo aprovada por unanimidade no dia 9 de março de 2010 no Rio de Janeiro - RJ. Essa diretriz se configurou como o grande marco na educação prisional, ficando o Estado responsável pela implementação de suas políticas para a educação no sistema carcerário.

Outro avanço importante nessa área educacional foi a criação da Lei n. ${ }^{\circ}$ 12.433 em 29 de junho de 2011, aprovada pela então presidenta Dilma Rousseff, que altera a LEP de 1984, incluindo o estudo como benefício para remissão da pena. Nesse mesmo ano, a presidenta baixou o Decreto n. ${ }^{\circ} 7.626$, que instituía o Plano Estratégico de Educação no âmbito do Sistema Prisional (PEESP), para ampliar e qualificar a promoção da educação nos estabelecimentos penais. Recentemente, no ano de 2013, o Ministro Joaquim Barbosa, presidente do Supremo Tribunal Federal, lançou a recomendação n. ${ }^{\circ} 44$ para todos os tribunais, destacando que:

Art. $1 .^{\circ}$ Recomendar aos Tribunais que:

I - para fins de remição pelo estudo (Lei no 12.433/2011), sejam valoradas e consideradas as atividades de caráter complementar, assim entendidas aquelas que ampliam as possibilidades de educação nas prisões, tais como as de natureza cultural, esportiva, de capacitação profissional, de saúde, entre outras, 
conquanto integradas ao projeto político-pedagógico (PPP) da unidade ou do sistema prisional local e sejam oferecidas por instituição devidamente autorizada ou conveniada com o poder público para esse fim; [...] V- [...]

d) para que haja a efetivação dos projetos, garantir que nos acervos das bibliotecas existam, no mínimo, 20 (vinte) exemplares de cada obra a ser trabalhada no desenvolvimento de atividades; e) procurar estabelecer, como critério objetivo, que o preso terá o prazo de 21 (vinte e um) a 30 (trinta) dias para a leitura da obra, apresentando ao final do período resenha a respeito do assunto, possibilitando, segundo critério legal de avaliação, a remição de 4 (quatro) dias de sua pena e ao final de até 12 (doze) obras efetivamente lidas e avaliadas, a possibilidade de remir 48 (quarenta e oito) dias, no prazo de 12 (doze) meses, de acordo com a capacidade gerencial da unidade prisional (BRASIL, 2013, p. 1).

Essa recomendação abre espaço para a valorização da cultura, projetos, leitura, organização do projeto político-pedagógico, entre outros, tornando-se também de grande valia para o incentivo do detento em procurar a educação como meio de formação intelectual e social, e principalmente a remissão de pena, que é o anseio de todos os apenados. Todavia, ainda há uma carência de profissionais capacitados para a implementação das diretrizes do ensino nas prisões.

\section{Educação como proposta política para a ressocialização}

O surgimento das Diretrizes Nacionais para a oferta de educação para jovens e adultos em situação de privação de liberdade nos estabelecimentos penais, em 2011, foi a mola propulsora para o seu desenvolvimento. Visam atender questões de ordem política de educação: [...] “o objetivo da 'diretriz' é apresentar elementos para a definição de uma política macro e não para particularidades regionais e/ou institucionais que deverão ser resolvidas localmente à luz das orientações contidas no Parecer e na Resolução" (BRASIL, 2010, p. 1).

De acordo com o Parecer CNE/CEB n. ${ }^{\circ} 4 / 2010$, nota-se que os estados ficam encarregados de formular as políticas públicas para a educação de jovens e adultos no sistema prisional, respeitando suas peculiaridades. Nessa direção, o Estado de Pernambuco, por meio da Secretaria Estadual de Educação e da Secretaria Estadual de Desenvolvimento Social e Direitos Humanos, realizou três encontros, no ano de 2010, para a formulação do Plano Estadual de Educação em Prisões de Pernambuco: 2013/2014, que 
apresentou algumas contradições entre o seu tema e o conteúdo abordado, objetivos e resultados.

O primeiro encontro teve como objetivo "instrumentalizar os profissionais que atuam nas Unidades Prisionais, acerca das Diretrizes Nacionais para Educação em Prisões [...]". Dentre as temáticas abordadas, destaca-se o Parecer CNE/CEB n. ${ }^{\circ} 4 / 2010$, Resolução CNE/CEB n. ${ }^{\circ}$ 2/2010, o currículo na educação em prisões e as perspectivas para a educação em prisões. $\mathrm{O}$ segundo encontro deu continuidade às temáticas do primeiro e acrescentou a função social da escola no processo de ressocialização; e, por fim, no terceiro encontro, debateu-se a remissão de pena e o processo de escrituração escolar do desempenho das aprendizagens dos estudantes.

Ao analisar esse plano, pode-se levantar alguns questionamentos, tais como: se objetivou-se instrumentalizar os profissionais, por que não aconteceu? Apresenta-se uma discussão sobre um currículo para educação em prisões, no entanto, o plano apresenta o mesmo currículo do ensino regular, então onde encontra-se o currículo mencionado nos objetivos do encontro? $\mathrm{Na}$ introdução do plano, é citado o tema referente à função da escola no processo de ressocialização, porém não se encontram vestígios desse tema no plano. Onde estão as propostas de ressocialização?

No item 5.1 desse plano, expressa-se que:

Em Pernambuco, não há um ato normativo que disponha sobre gestão compartilhada do Sistema Prisional entre as Secretaria de Desenvolvimento Social e Direitos Humanos / Secretaria de Desenvolvimento Social e Direitos Humanos / Secretaria de Ressocialização e Secretaria de Educação. Portanto, conta-se uma lacuna normativa no que se refere às atribuições e competências das duas secretarias de governo no âmbito dos espaços prisionais (PERNAMBUCO, 2012, p. 22).

Por que não existe nenhum ato normativo sobre a gestão compartilhada entre as secretarias? Esse é um grande questionamento a ser levantado para compreender como se dá a articulação dessa gestão. Não obstante, o plano continua a revelar sua fragilidade na organização e normatização da educação no sistema prisional:

No que tange a oferta da Educação de Jovens e Adultos (EJA) nos estabelecimentos prisionais, não há, no âmbito do Estado de Pernambuco, nenhuma portaria, resolução ou instrução normativa que versem sobre a temática educação em prisões. Os documentos legais que regulam a oferta de educação prisional são os mesmos usados para qualquer estabelecimento educacional da Rede Pública Estadual (PERNAMBUCO, 2012, p. 23). 
Essa é uma das declarações mais provocantes e confusas. Há um Plano Estadual de Educação em Prisões de Pernambuco que não trata da educação em prisões, e sim da educação regular. Todos esses questionamentos podem ser objeto de uma pesquisa mais aprofundada sobre a educação prisional no estado de Pernambuco. Contudo, o estado sai na frente com $29 \%$ dos presos envolvidos em atividades educacionais, enquanto a média nacional é de 10\%.

Apesar das dificuldades e da escassez de atos normativos e de um plano específico para as prisões, a Escola Estadual Bento XVI, loco dessa pesquisa, no uso de suas atribuições, cumpre com algumas dificuldades o seu papel, empenhando-se para atender as determinações das diretrizes nacionais para educação em prisões. Em seu Projeto Político Pedagógico (PPP), a escola apresenta de forma tímida a educação ressocializadora, estando mais coerente com essa modalidade de ensino que o próprio plano estadual. A instituição cumpre as exigências do Parecer CNE/CEB n. ${ }^{\circ} 4 / 2010$, no que tange os seguintes aspectos: a instituição atende as diversas modalidades de ensino, ofertadas nos diferentes turnos, realiza atividades complementares, organiza-se para atender as peculiaridades de tempo, espaço e rotatividade ${ }^{6}$.

A instituição pesquisada dispõe de estrutura adequada, ou seja, foi construída em espaço apropriado dentro do presídio, dispondo de 10 salas de aula, sendo 2 no feminino, 2 no semiaberto e 6 no ambiente interno, banheiros femininos e masculinos, secretaria, diretoria, sala de coordenação, sala de leitura, cozinha e almoxarifado. Possui equipamentos básicos como 1 projetor, 4 bebedouros, 2 TVs, 2 computadores para uso da coordenação, professores e secretária e 1 impressora multifuncional. Em entrevista com a gestora adjunta, a mesma relatou as necessidades estruturais: "Estamos com o projeto de construção de uma quadra poliesportiva, e precisamos de uma biblioteca, máquina de xerox e aparelho de DVD, visando proporcionar aos reeducandos maiores possibilidades de enriquecimento cultural".

Outro aspecto a ser enfatizado, segundo ela, é a falta de capacitação específica para o ensino nas prisões, uma vez que o estado oferece a mesma capacitação do ensino regular. As diretrizes, em seu Artigo 11, afirma que: "Educadores, gestores e técnicos que atuam nos estabelecimentos penais deverão ter acesso a programas de formação inicial e continuada que levem em consideração as especificidades da política de execução penal" (BRASIL, 2010).

6

Art. $2 .^{\circ}:[\ldots]$ devendo atender às especificidades dos diferentes níveis e modalidades de educação e ensino e são extensivas aos presos provisórios, condenados, egressos do sistema prisional e àqueles que cumprem medidas de segurança. Art. $3 .^{\circ}:$ [...] III - estará associada às ações complementares de cultura, esporte, inclusão digital, educação profissional, fomento à leitura e a programas de implantação, recuperação e manutenção de bibliotecas destinadas ao atendimento à população privada de liberdade, inclusive as ações de valorização dos profissionais que trabalham nesses espaços; [...] VII - comtemplará o atendimento em todos os turnos. VIII - será organizada de modo a atender às peculiaridades de tempo, espaço e rotatividade da população carcerária levando em consideração a flexibilidade prevista no art. 23 da Lei n. ${ }^{\circ}$ 9.394/96 (LDB). (BRASIL, 2010, p. 29). 
Segundo Onofre (2012), a implementação de políticas públicas pautadas na qualidade e equidade no campo educacional não pode deixar de contemplar questões relativas à formação docente. $\mathrm{O}$ maior entrave encontrado na instituição pesquisada, foi a falta de professores qualificados para exercer a função de ressocializadores.

Nesse sentido, os educadores que atuam nesse contexto necessitam conhecer o meio em que estão inseridos e valorizar os conhecimentos anteriores dos detentos. Durante observações realizadas em uma das turmas da Escola Bento XVI, uma professora expôs que: "a maior dificuldade que encontramos para identificar as estratégias adequadas para cada turma é que a maioria dos detentos não possui sequer o registro de nascimento, criando pseudonomes e forjando um nível de escolaridade que não possui" (informação verbal). Esse é um dos problemas enfrentados pelos professores, isto é, os detentos forjam uma escolaridade que não possuem e não conseguem acompanhar a turma na qual estão matriculados, por pura vaidade e autopromoção.

Outro quadro apresentado por uma professora é a dificuldade de dar sequência aos conteúdos, pois detentos ficam à mercê dos agentes penitenciários; se ocorre uma revista nos pavilhões, motim ou qualquer outro problema, ficam impedidos de ir à escola naquele dia. A educadora ainda ressaltou que:

Falta uma sensibilidade por parte dos agentes, um olhar peda-
gógico, ainda possuem uma visão arcaica de que, 'bandido bom
é bandido morto'. Somos muitas vezes vistos como inferiores
por parte deles, e a qualquer momento presenciamos nossos
alunos serem revistados e maltratados no espaço educacional
(informação verbal).

Em toda a pesquisa, não se detectou nenhum desrespeito por parte dos apenados aos professores e outros profissionais da escola. Pelo contrário, eles são participativos, colaboram para o bom desenvolvimento da aula, e o maior problema ainda é o preconceito da sociedade que não acredita em uma recuperação. Teixeira (2007, p. 20) afirma que: “As prisões não podem continuar sendo um assunto de poucos e os presos não podem continuar 'invisíveis' para a sociedade nem glamourizados, nem demonizados pela mídia”. Essa é uma das grandes barreiras a serem quebradas para que de fato a educação cumpra seu papel nos espaços prisionais. Julião (2007, p. 4) ressalta que "Quem se 'ressocializa' geralmente o faz por conta própria, pois, em uma avaliação mais aprofundada dos fatos, poucas são as propostas do Estado existentes para tal."

Tratando da ressocialização, entende-se que, para que de fato ela aconteça, é preciso uma ação conjunta entre gestores da penitenciária, gestor escolar, agentes policiais e educadores. "Responsabilizar a educação pela ressocializa- 
ção dos presos é exigir mais do que se deve da educação; a reinserção do preso na sociedade é dever do sistema penitenciário, como prevê a Lei de Execução Penal e depende de um tratamento penal concebido para que isto ocorra." (TEIXEIRA, 2007, p. 20).

Sabe-se que a educação tem o papel de ajudar o ser humano a desenvolver habilidades e capacidades para mudar a sua condição de vida e disputar oportunidades na sociedade. Ireland (2011, p. 20) afirma que: "A educação busca expandir os horizontes físicos, éticos e intelectuais, contribuindo para o pleno desenvolvimento e a libertação do ser humano." A escola tem que cumprir esse importante papel de munir os apenados com recursos intelectuais, para que as dificuldades outrora encontradas por falta de conhecimentos sejam minimizadas.

A maioria dos professores que atuam nas penitenciárias não optaram por esse trabalho, mas algumas circunstâncias os levaram até lá. Então, torna-se necessário o aperfeiçoamento dos instrumentos para seleção de professores realmente com vontade de atuar nesse cenário desafiador. Ao término das observações e entrevistas, surpreende a indagação de uma professora: "Com todos os entraves presenciados nessa pesquisa, acredita-se que ainda exista uma esperança de ressocialização?" Esse é um questionamento pessimista que tem invadido todo o cenário educacional, não só os da prisão. Contudo, confia-se em uma educação reparadora das desigualdades sociais existentes. Portanto, o sistema prisional tem que se preocupar em desenvolver capacidades crítica e criadora do educando, levando-o a refletir sobre as possibilidades de escolhas e a importância dessas escolhas para a sua vida e do seu grupo social (SANTOS, 2005).

No que tange a educação superior, a gestora adjunta relatou que esse processo se dá por meio do Exame Nacional do Ensino Médio (ENEM) prisional, mas até então não foram registradas aprovações de nenhum estudante da instituição.

A instituição cumpre com seu papel indo a cada pavilhão, divulgando as ofertas de vagas para matrículas dos detentos; são ofertadas 25 vagas por turma. Em entrevista com a gestora adjunta, indagou-se acerca de sua relação com o gestor da penitenciária. Esse é um diferencial da escola Estadual Bento XVI. Ela respondeu que a relação se dá de maneira muito boa, havendo o apoio do mesmo nas ações educativas.

\section{Considerações finais}

A ressocialização por meio da educação é uma temática bastante complexa que exige um aprofundamento de estudos por parte dos verdadeiros agentes desse processo, os educadores que atuam nessa desafiadora missão. 
A instituição objeto dessa pesquisa revelou-se vulnerável às políticas públicas do Estado. Mesmo existindo uma secretaria específica de ressocialização, não existe sequer um ato normativo no sentido de melhorar esse ensino. Outro percalço encontrado é a falta de capacitações específicas para o ensino no sistema prisional e, por conseguinte, profissionais qualificados para exercer essa função.

Apesar de não possuírem incentivo e implementação do governo para esses profissionais da educação, vale salientar que eles se esforçam para cumprir o seu papel e, na medida do possível, dar uma educação de qualidade para os reclusos. Mesmo com um plano estadual descontextualizado, a instituição não hesitou em formular o seu Projeto Político-Pedagógico (PPP), enquadrando-o às diretrizes nacionais e esforçando-se para cumprir com o seu dever, no entanto nem sempre os educadores estão de acordo com as propostas apresentadas no PPP.

No que diz respeito à estrutura física, a instituição possui um espaço desejado por muitos reclusos em todo país, que ainda estudam em "celas de aula", ao em vez de salas de aula. Há esperanças para a formação inicial e continuada específicas para os professores: segundo a gestora adjunta, o Ministério da Educação (MEC) prevê a promoção dessa capacitação para o ano de 2015.

Um dos entraves nesse processo de formação de professores para o sistema prisional é a falta de discussão da temática nas universidades. Destaca-se a Universidade de Pernambuco, que em suas licenciaturas nem mesmo aborda o assunto, tornando-o desconhecido e obscuro aos estudantes.

Esse trabalho não esgota a investigação sobre a temática, por ser um assunto abrangente e complexo de se explicar em pouco tempo de pesquisa, mas traz contribuições para os leitores que desejam iniciar no mundo da pesquisa. Pensar em uma educação de qualidade dentro dos presídios brasileiros implica em quebrar os paradigmas preconceituosos fixados pela sociedade, dando espaço para uma educação de fato ressocializadora.

\section{Referências}

ÁVILA, Virgínia Pereira da Silva. História do ensino primário rural em São Paulo e Santa Catarina (1921-1952). Cultura Acadêmica, São Paulo, 2013. Disponível em: $<$ http://culturaacademica.com.br/_img/arquivos/9788579834875.pdf>. Acesso em: 26 nov. 2014.

BRASIL. Constituição Política Do Império Do Brasil (1824). Carta de Lei de 25 de março de 1824. Disponível em: <http://www.planalto.gov.br/ccivil_03/constituicao/Constituicao24. htm>. Acesso em: 26 nov. 2014. 
Lei n. ${ }^{\mathbf{0}}$ 16, de 12 de agosto de 1834 . Faz algumas alterações e adições à Constituição Política do Império, nos termos da Lei de 12 de outubro de 1832. Disponível em: <http:// www2.camara.leg.br/legin/fed/lei/1824-1899/lei-16-12-agosto-1834-532609-publicacaooriginal-14881-pl.html>. Acesso em: 26 nov. 2014.

Lei n. 7.210, de 11 de julho de 1984. Institui a Lei de Execução Penal. Disponível em:

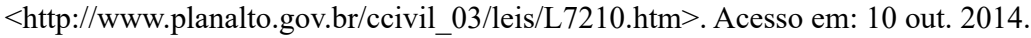

Constituição da República Federativa do Brasil de 1988. Disponível em: <http://www. planalto.gov.br/ccivil_03/constituicao/constituicaocompilado.htm>. Acesso em: 10 out. 2014.

Conselho Nacional de Política Criminal e Penitenciária. Resolução n. 14, de 11 de novembro de 1994. Disponível em: <http://www.crpsp.org.br/interjustica/pdfs/regras-minimas -para-tratamento-dos-presos-no-brasil.pdf>. Acesso em: 10 out. 2014.

. Lei complementar n. ${ }^{0}$ 79, de 07 de janeiro de 1994. Cria o Fundo Penitenciário Nacional - FUNPEN. Disponível em: <http://www.planalto.gov.br/ccivil_03/leis/lcp/Lcp79. htm>. Acesso em: 24 nov. 2014.

Resolução n. ${ }^{0}$ 14, de 11 de novembro de 1994. Regras mínimas para o tratamento de Presos no Brasil. Conselho Nacional de Política Criminal e Penitenciária. Disponível em: $<$ http://portal.mj.gov.br/data/pages/mje9614c8citemidd4ba0295587e40c6a2c6f741cf662e79ptbrie.htm>. Acesso em: 25 nov. 2014.

Lei n. ${ }^{\circ} 9.394$ de dezembro de 1996. Lei de diretrizes e bases da educação nacional n. ${ }^{\circ}$ 9394/96. Disponível em: <http://www.planalto.gov.br/ccivil_03/leis/19394.htm>. Acesso em: 26 nov. 2014.

. Parecer n. ${ }^{\mathbf{0}}$ 11/2000, aprovado em 10 mai. 2000. Diretrizes Curriculares Nacionais para a Educação de Jovens e Adultos. Conselho Nacional de Educação/Câmara de Educação Básica. Disponível em: <http://portal.mec.gov.br/secad/arquivos/pdf/eja/legislacao/parecer_11_2000.pdf $>$. Acesso em: 05 jul. 2014.

Lei n. ${ }^{\mathbf{0}}$ 10.172, de 9 de janeiro de 2001. Aprova o Plano Nacional de Educação e dá outras providências. Disponível em: <http://www.planalto.gov.br/ccivil_03/leis/leis 2001/ 110172.htm>. Acesso em: 25 nov. 2014.

Ministério da Educação. Programa Brasil Alfabetizado: novo. Brasília, 2003. Dis-

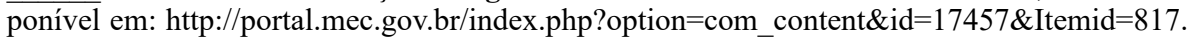
Acesso em: 26 nov. 2014.

Comitê Nacional de Educação em Direitos Humanos. Plano Nacional de Educação em Direitos Humanos. Brasília: Secretaria Especial dos Direitos Humanos; Ministério da Educação, 2003. Disponível em: <http://www.observatoriodeseguranca.org/files/pnedh.pdf>. Acesso em: 25 nov. 2014.

Lei n. 11.530, de 24 de outubro de 2007. Institui o Programa Nacional de Segurança Pública com Cidadania - PRONASCI e dá outras providências. Disponível em: $<$ http://www. planalto.gov.br/ccivil_03/_ato2007-2010/2007/Lei/L11530.htm>. Acesso em: 10 out. 2014.

Lei n. 11.707, de 19 de junho de 2008. Altera a Lei no 11.530 , de 24 de outubro $\overline{\text { de } 2007}$, que institui o Programa Nacional de Segurança Pública com Cidadania - Pronasci. 
Disponível em: <http://www.planalto.gov.br/ccivil_03/_ato2007-2010/2008/Lei/L11707.htm>. Acesso em: 10 out. 2014.

Parecer CNE/CEB n. ${ }^{\mathbf{4}} \mathbf{4 / 2 0 1 0}$, aprovado em 9 mar. 2010. Diretrizes nacionais para a oferta de educação para jovens e adultos em situação de privação de liberdade nos estabelecimentos penais. Conselho Nacional de Educação/Câmara de Educação Básica. Disponível em: $<$ http://portal.mec.gov.br/index.php?option=com_content\&view=article\&id=12764\&Itemid=866> . Acesso em: 05 jul. 2014.

. Resolução CNE/CEB n. ${ }^{0}$ 2, de 19 de maio de 2010.Diretrizes nacionais para a oferta de educação para jovens e adultos em situação de privação de liberdade nos estabelecimentos penais. Conselho Nacional de Educação/Câmara de Educação Básica. Disponível em: <http:// portal.mec.gov.br/index.php?option=com_content\&view=article\&id=12816\&Itemid=866>. Acesso em: 05 jul. 2014.

. Lei n. 12.433, de 29 de junho de 2011. Altera a Lei no 7.210, de 11 de julho de 1984 (Lei de Execução Penal), para dispor sobre a remição de parte do tempo de execução da pena por estudo ou por trabalho. Disponível em: <http://www.planalto.gov.br/CCivil_03/_Ato20112014/2011/Lei/L12433.htm>. Acesso em: 10 out. 2014.

Decreto n. ${ }^{\mathbf{7}}$ 7.626, de 24 de novembro de 2011. Institui o Plano Estratégico de Educação no âmbito do Sistema Prisional. Disponível em: <http://www.planalto.gov.br/ccivil_03/_ Ato2011-2014/2011/Decreto/D7626.htm>. Acesso em: 25 nov. 2014.

. Conselho Nacional de Justiça. Recomendação n. 44 de 26 de novembro de 2013. Dispõe sobre atividades educacionais complementares para fins de remição da pena pelo estudo e estabelece critérios para a admissão pela leitura. Disponível em: $<$ http://www.cnj.jus.br/ busca-atos-adm?documento=1235>. Acesso em: 10 out. 2011.

CAJUEIRO, Roberta Liana Pimentel. Manual para elaboração de trabalhos acadêmicos: guia prático do estudante. Rio de Janeiro: Saraiva, 2013. 159 p.

CERATTI, Márcia Rodrigues Neves. Políticas públicas para a educação de jovens e adultos. SEED/PR, 2007. Disponível em: <http://www.gestaoescolar.diaadia.pr.gov.br/arquivos/ File/producoes_pde/md_marcia_rodrigues_neves_ceratti.pdf $>$. Acesso em: 03 jul. 2014.

COSTA, Enio Silva da. Educar para libertar: por uma política educacional para o sistema prisional brasileiro. Revasf, Petrolina, PE, v. 03, n. 1, p. 61-76, ago. 2014. Disponível em: <http:// www.periodicos.univasf.edu.br/index.php/revasf/article/download/447/211>. Acesso em: 21 nov. 2014.

FRIEDRICH, Marcia et al. Trajetória da escolarização de jovens e adultos no Brasil: de plataformas de governo a propostas pedagógicas esvaziadas. Ensaio: aval. pol. públ. Educ., Rio de Janeiro, v. 18, n. 67, p. 389-410, abr./jun. 2010. Disponível em: <http://www.scielo.br/pdf/ ensaio/v18n67/a11v1867.pdf>. Acesso em: 22 nov. 2014.

IRELAND, Timothy D. Educação em prisões no Brasil: direito, contradições e desafios. Em Aberto, Brasília, v. 24, n. 86, p. 19-39, nov. 2011. Disponível em: <http://emaberto.inep.gov. br/index.php/emaberto/article/view/2651/1875>. Acesso em: 1 dez. 2014.

JULIÃO, Elionaldo Fernandes. Educação para jovens e adultos privados de liberdade: desafios para a política de reinserção social. Salto para o Futuro, boletim 6, p. 3-13, maio 2007. 
MARREIROS, Natanael Ítalo Aleixo da Costa. Do direito à educação à perspectiva ressocializadora...

Disponível em: <http:/www.tvbrasil.org.br/fotos/salto/series/154418Educacaoprisional.pdf>. Acesso em: 8 dez. 2014.

A ressocialização por meio do estudo e do trabalho no sistema penitenciário brasileiro. Em Aberto, Brasília, v. 24, n. 86, p. 141-155, nov. 2011. Disponível em: <http://emaberto.inep. gov.br/index.php/emaberto/article/view/2651/1875>. Acesso em: 1 dez. 2014.

ONOFRE, Elenice Maria Cammarosano. Desafio histórico na educação prisional brasileira: ressignificando a formação de professores... Um quê de utopia? HISTEDBR On-line, Campinas, n. 47, p. 205-219, set. 2012. Disponível em: <http://www.fe.unicamp.br/revistas/ged/ histedbr/article/download/4214/3420>. Acesso em: 2 dez. 2014.

ONU - ORGANIZAÇÃO DAS NAÇÕES UNIDAS. Regras Mínimas para o Tratamento de Prisioneiros. In: CONGRESSO DAS NAÇÕES UNIDAS - PREVENÇÃO DO CRIME E TRATAMENTO DE DELINQUENTES, 1., Genebra, 1955. Disponível em: <http://www. defensoria.sp.gov.br/dpesp/repositorio/0/documentos/n\%C3\%BAcleos $\% 20$ especializados/REGRAS\%20M\%C3\%8DNIMAS\%20PARA\%20O\%20TRATAMENTO\%20DE\%20PRISIONEIROS.pdf $>$. Acesso em: 10 out. 2011.

OTONI, Nilo; FIALHO, Francisco Antonio Pereira. TCC: métodos e técnicas. 2. ed. rev. atual. Florianópolis: Visual Books, 2011. 160 p.

PERNAMBUCO. Decreto n. ${ }^{\circ}$ 37717, de 29 de dezembro de 2011. Diário Oficial do Estado de Pernambuco, Recife, PE, 29 dez. 2011. Disponível em: <http://www.jusbrasil.com.br/diarios/44515551/doepe-30-12-2011-pg-5>. Acesso em: 21 nov. 2014.

2012.

Plano estadual de educação em prisões de Pernambuco: 2013/2014. Recife, nov.

Projeto Político Pedagógico. Escola Estadual Bento XVI. Petrolina, 2014. DOCX.

PIERRO, M. C.; JOIA, O; RIBEIRO, V. M. Visões da educação de jovens e adultos no Brasil. Cadernos Cedes, n. 55, p. 58-77, nov. 2001. Disponível em: $<$ http://www.scielo.br/pdf/ccedes/ v21n55/5541.pdf > . Acesso em: 26 nov. 2014.

PORTAL BRASIL. Educação: levantamento mostra escolaridade dos presidiários no País. 28 jul. 2014. Disponível em: <http://www.brasil.gov.br/educacao/2012/04/levantamento-mostra -escolaridade-dos-presidiarios-no-pais $>$. Acesso em: 10 out. 2011.

SANTOS, Sintia Menezes. Ressocialização através da educação. Direitonet, 2005. Disponível em: < http://www.direitonet.com.br/artigos/exibir/2231/Ressocializacao-atraves-da-educacao $>$. Acesso em: 06 jun. 2014.

SILVA, Mazukyevicz Ramon Santos do Nascimento. Educação prisional no Brasil: do ideal normativo às tentativas de efetivação. Âmbito Jurídico, Rio Grande, v 14, n. 87, abr. 2011. Disponível em: <http://www.ambito-juridico.com.br/site/index.php?n_link=revista_artigos_ leitura\&artigo_id=9362>. Acesso em: 26 nov. 2014.

STRELHOW, Thyeles Borcarte. Breve história sobre a educação de jovens e adultos no Brasil. HISTEDBR On-line, Campinas, n. 38, p. 49-59, jun. 2010. Disponível em: <http://www. fe.unicamp.br/revista/index.php/histedbr/article/view/3520/310>. Acesso em: 30 jun. 2014. 
TEIXEIRA, Carlos José Pinheiro. O papel da educação como programa de reinserção social para jovens e adultos privados de liberdade: perspectivas e avanços. Salto para o Futuro, boletim n. 6, p. 14-21, maio 2007. Disponível em: <http://www.tvbrasil.org.br/fotos/salto/series/154418Educacaoprisional.pdf>. Acesso em: 2 dez. 2014.

Submissão em: 29/12/2014

$1^{a}$. revisão em: 13/07/2015

$2^{\mathrm{a}}$. revisão $18 / 07 / 2016$

Aceite em: 21/07/2016

Natanael Ítalo Aleixo da Costa Marreiros é graduado em Pedagogia pela Universidade de Pernambuco (2014). Atualmente cursando Pós-Graduação em Psicopedagogia e Supervisão Escolar na Universidade Candido Mendes.

E-mail: natanael.italo2013@gmail.com 